\title{
Numerical Simulation on Large Deformation of Weak Rock Mass Tunnel Under High Geostress
}

\author{
Feng Zhou ${ }^{1}$, Hongjian Jiang ${ }^{2, a}$ and Xiaorui Wang ${ }^{2,3}$ \\ ${ }^{1}$ Luo Yang Jing Xin Highway Engineering Technology Development Co.,Ltd., Luoyang 471000, China. \\ ${ }^{2}$ Institute of Resoursces \& Enviroument, North China University of Water Resources and Electric Power, Zhengzhou 450000, China. \\ ${ }^{3}$ Zheng Zhou Subway Construction Co., Ltd., Zhengzhou 450000, China.
}

\begin{abstract}
The problem about the stability of tunnel surrounding rock is always an important research object of geotechnical engineering, and the right or wrong of the result from stability analysis on surrounding rock is related to success or failure of an underground project. In order to study the deformation rules of weak surrounding rock along with lateral pressure coefficient and burying depth varying under high geostress and discuss the dynamic variation trend of surrounding rock, the paper based on the application of finite difference software of FLAC3D ,which can describe large deformation character of rock mass, analog simulation analysis of surrounding rock typical section of the class II was proceeded. Some conclusions were drawn as follows: (1) when burying depth is invariable, the displacements of tunnel surrounding rock have a trend of increasing first and then decreasing along with increasing of lateral pressure coefficient. The floor heave is the most sensitive to change of lateral pressure coefficient. The horizontal convergence takes second place. The vault subsidence is feeblish to change of lateral pressure coefficient. (2) The displacements of tunnel surrounding rock have some extend increase along with increasing of burying depth. The research conclusions are very effective in analyzing the stability of surrounding rock of Yunling tunnel. These are going to be a reference to tunnel supporting design and construction.
\end{abstract}

\section{Introduction}

The impact of high geostress on geotechnical engineering is significant, especially for underground engineering such as deep-buried mining tunnels, railways and road tunnels with large depth and weakness. With the development of Chinese traffic construction, tunneling has grown to longer, bigger and deeper.

In recent years, large and medium-sized tunnels in soft and weak surrounding rock are emerging, which go through geostress areas and poor geological environment. Due to the lack of adequate understanding of the weak geological environment in the geostress area, accidents such as landslides and over-deformation of the lining frequently occur during the tunnel construction, causing huge losses to the tunnel construction. For example, Jiazhuqing Tunnel, which is located in the nankun line, the length of the tunnel is $4.99 \mathrm{~km}$ and its lateral pressure coefficient is 1.88 . When the tunnel into the $404 \mathrm{~m}$ depth of the coal strata, due to the lower coal seam strength and the presence of knotty cemented sandstone and mudstone with joint development, the integrity of the tunnel is poor. Under the action of high ground stress, the shotcrete and bolt support successively deform seriously. The crown sinking deformation of $80 \sim 100 \mathrm{~cm}$, the floor drum deformation $50 \sim 80 \mathrm{~cm}$ and both sides of the wall inward shift $50 \sim 60 \mathrm{~cm}$. The steel frame due to deformation of the surrounding rock warping, spray layer cracking and detachment from the steel(Zhiqiang Zhang and Baoshu Guan, 2000). Wuqiaoling Tunnel is known as Asia's first long tunnel, its length is $20.05 \mathrm{~km}$. When it passes through the deep rock 450 1100m in Wuweiduan phyllite splint rock and other soft rock areas and in the 15 33MPa geostress under the action of large deformation, the maximum deformation of nearly $1000 \mathrm{~mm}$ and the average deformation of $400 \sim 600 \mathrm{~mm}$. Resulting in a great deformation of the strong initial support was damaged, and seriously damaged the tunnel lining, as a result, the initial support has to be demolished in whole or in part and seriously affect the construction safety and construction schedule(Jikui Zhang and Junbo Fang, 2005).

In this paper, the finite difference software FLAC3D is used to simulate the tunnel excavation process under high ground stress, and the displacement of surrounding rock caused by the change of buried depth and lateral pressure coefficient is discussed. The obtained data and conclusions not only provide the basis for optimizing the supporting system of the tunnel, but also guide the construction of the tunnel on site. And they are expected to provide useful reference and reference for the design, construction and research of similar tunnels.

\footnotetext{
a Corresponding author: 1592171001@qq.com
} 


\section{Theoretical basis}

\subsection{The basic principle of FLAC3D software}

The basic principle of FALC3D software is the Lagrangian difference method, which uses a hybrid discrete method to discrete the region into a collection of often-distorted hexahedron elements and treats each hexahedron as a constant-strain tetrahedron with hexagonal corner points as corners. The variables such as stress, strain and node unbalance force are calculated on tetrahedron. The stress and strain of hexahedron are the volume weighted average of the tetrahedron inside. This method not only avoids the displacement shear locking phenomenon often encountered in the regular hexahedron elements, but also makes the displacement patterns of the tetrahedral elements fully meet some constitutive requirements, such as incompressible plastic flow.

The calculation cycle of the Lagrangian method is based on the assumption that the speed of each node at a given time is known. According to Gauss's theorem to get the unit of the strain rate, and then according to the material constitutive relationship obtained for each unit of new stress, then go to the next calculation cycle (Coetzee, M. J., R. D. Hart, P. M. Varona, et al., 1988).

Strain tensor is expressed in incremental form:

$$
\Delta e_{i j}=\frac{1}{2}\left|\frac{\partial \dot{u}_{i}}{\partial x_{j}}+\frac{\partial \dot{u}_{j}}{\partial x_{i}}\right| \Delta t
$$

In this formula, $\triangle \mathrm{e}_{i j}$ represents the tensor of the increment; $i, j=1,2 ; i, j$ represents the velocity component of the node; $x i$ is the coordinate of the node; $\triangle t$ is the amount of time change.

According to Gauss's theorem, for tetrahedral elements:

$$
\int_{V} v_{i, j} d V=\int_{S} v_{i} n_{j} d S
$$

According to the constitutive relationship of the material, the increment of stress is obtained:

$$
\Delta \sigma_{i j}=f\left(\Delta e_{i j}, \sigma_{i j}, \cdots\right)
$$

In this formula, $f$ denotes the function of the constitutive relation, it relates to increment of strain, original total stress and material constant.

The unbalanced force $F_{\mathrm{i}}$ acting on each node can be obtained by integrating the lines around the node $\mathrm{O}$ to the stress lines.

The unbalanced forces at each node at $\mathrm{t}$ and $t+\Delta t \mathrm{can}$ be calculated by the same method. The acceleration of a node at $t+\Delta t / 2$ can be found by the following difference format

$$
\dot{u}(t+\Delta t / 2)=\dot{u}(t-\Delta t / 2)+\frac{F_{i}^{(t)}}{m}+g_{i}
$$

This completes a calculation cycle, and then the cycle of the next round of time $\Delta t$, so calculated until the problem converges, or the problem itself does not converge (such as the occurrence of plastic flow), then you can track the plastic flow process.

\subsection{Introduction to the Mohr - Coulomb Model}

The failure criterion for the model is the MohrCoulomb criterion for tensile shear combinations (Bo Liu and Yanhui Han, 2005). This criterion can be explained in Figure 1. Describe the destruction of the envelope from point A to point B using the MohrCoulomb failure criterion $f^{s}=0$ :

$$
f^{s}=\sigma_{1}-\sigma_{3} N+2 c \sqrt{\frac{1+\sin (\phi)}{1-\sin (\phi)}}
$$

Describe the envelope from point $\mathrm{B}$ to point $\mathrm{C}$ using the type of tensile failure criterion:

$$
f^{t}=\sigma_{3}-\sigma^{t}
$$

In this formula, $\phi$ is the friction angle, $c$ is the cohesion, $\sigma^{t}$ is the tensile strength, and the tensile strength does not exceed $\sigma_{3}$.

The maximum value is given by the following formula:

$$
\sigma_{\max }^{t}=\frac{c}{\tan \phi}
$$

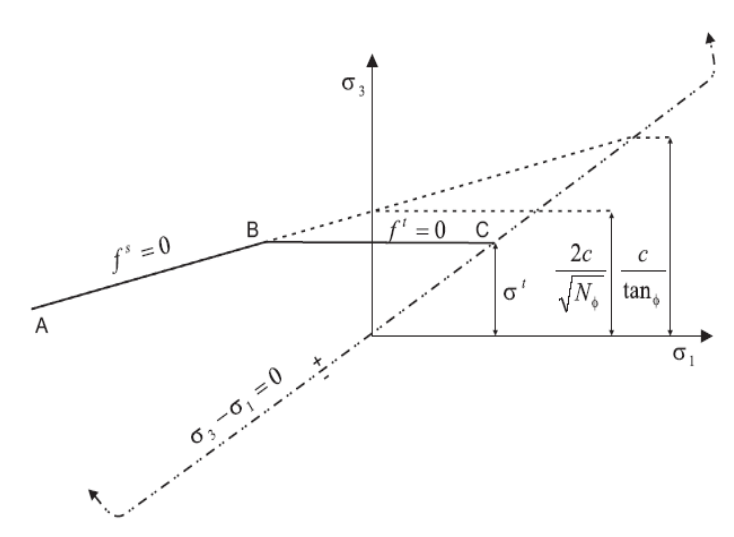

Figure.1 Damage criterion of Mohr-Coulomb

\section{Engineering background}

The entrance of Yunling Tunnel is located in Dingjiawan Village, Shangjin Town, Yunxi County, Hubei Province. Its exit is located in Manchuanguan, Shanxi Province. It is an isolated tunnel with four-lane expressway. The left line is located between ZK104 + 760 ZK106 +940, the total length is about $2180 \mathrm{~m}$, and the right line is located at YK104 + $755 \sim$ YK106 $+940 \mathrm{~m}$ with a length of $2185 \mathrm{~m}$.

The topography of Yunling Tunnel Area has a large topography with a relative elevation difference of about $350 \mathrm{~m}$. The depth of the tunnel is between $100 \mathrm{~m}$ and $350 \mathrm{~m}$ and the maximum depth is $344 \mathrm{~m}$. The tunnel is 
located in the southern margin of the Indo-China orogenic belt in the South Qinling Mountains and has a complex geological structure. Mainly for a series of north-west distribution of the two Yun faults and folds. The research scope of this dissertation is the type II surrounding rock sections with large depth, the tunnel surrounding rock is weakly weathered phyllite with high carbon content, and the rock components are chlorite, sericite, illite and albite. Rocky $c, \varphi$ value is very low, rock strength is low, belong to soft rock.

\section{Tunnel numerical simulation modeling}

\subsection{Model range and boundary conditions}

The range of numerical calculation of underground engineering generally takes $3 \sim 5$ times of excavation section.(Yongxu Xia and Yongdong Wang, 2004) According to the actual boundary of the problem, specify the direction along the tunnel to increase the $\mathrm{y}$-axis positive direction, the vertical upward $\mathrm{z}$-axis, tunneling cross-section to the left for the positive $\mathrm{x}^{-}$ axis. The calculation range selected as: in the $\mathrm{x}$-axis direction take $60 \mathrm{~m}$, the vertical $\mathrm{z}$-axis direction to take $50 \mathrm{~m}$, the tunnel axis $\mathrm{y}$-axis direction to take $50 \mathrm{~m}$. The selected boundary has exceeded the excavation of the cavern (greater than 3 times the hole diameter). The calculation area is divided into 35200 units and 36644 nodes to ensure that the calculation has sufficient accuracy. Its constraints (Itasca Consulting Group, Inc., 1997): horizontal boundary constraints on both sides of the border, the vertical direction of freedom; the bottom boundary of the vertical constraint, horizontal free; the top of the free surface. Grid model shown in Figure 2.

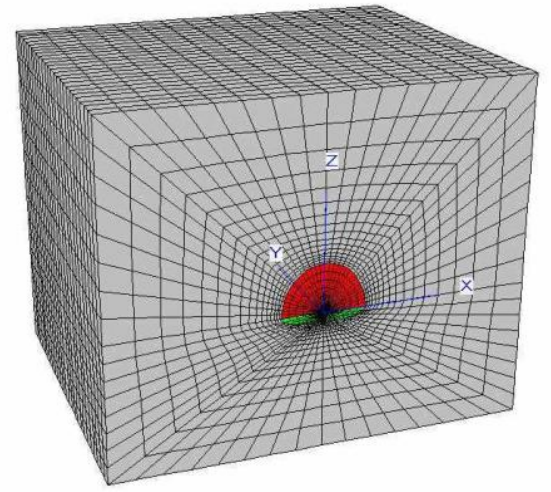

Figure.2 Calculated model and meshed division

\subsection{Calculation parameters selected}

In the calculation of FLAC3D, the mechanical parameters that need to be input into the rock are the bulk modulus $(K)$, shear modulus $(G)$, density $(\rho)$, cohesion $(C)$, internal friction angle $(\varphi)$ and tensile strength $\left(\sigma^{\prime}\right)$. Among them, the bulk modulus and the shear modulus are difficult to obtain by general methods and can be calculated according to the elastic mechanics formula provided by FLAC3D

$$
K=\frac{E}{3(1-2 \mu)} \quad G=\frac{E}{2(1+\mu)}
$$

In this formula, $E$ is modulus of elasticity, $\mu$ is Poisson's ratio.

According to the rock mechanics test data of Yunling Tunnel and Handbook of Rock Mechanics Parameters (Institute of Hydraulic and Electric Engineering, 1991), the mechanical parameters of rock mass in this study area are comprehensively analyzed. The material parameters of the model are shown in Table 1.

\subsection{Analyze the calculation results}

In order to analyze the influence of lateral pressure coefficient variation on the displacement of surrounding rock, this paper aims at analyzing the influence of lateral pressure coefficient on the displacement of surrounding rock at different depths $(100 \mathrm{~m}, 150 \mathrm{~m}, 200 \mathrm{~m}, 300 \mathrm{~m})$. The horizontal convergence of tunnel surrounding rock, vault subsidence and bottom drum were calculated and analyzed under different lateral pressure coefficients (Figures 3 5). The results obtained (Table 2) are analyzed as follows.

\subsubsection{Influence analysis of side pressure coefficient}

Under certain depth, with the increase of lateral pressure coefficient, the horizontal convergence, dome subsidence and bottom drum displacement all showed the trend of first increasing and then decreasing. When the burial depth is $100 \mathrm{~m}$, the horizontal convergence increases by $12.3 \%$, the dome sinking increases by $0.5 \%$ and the bottom drum increases by $36.4 \%$ in the range of variation where the displacement increases with increasing lateral pressure coefficient. When the burial depth is $150 \mathrm{~m}$, the horizontal convergence increases by $39.6 \%$, the vault sinking increases by $5.8 \%$ and the bottom drum increases by $283.9 \%$ in the range of variation where the displacement increases with increasing lateral pressure coefficient. When the depth is $200 \mathrm{~m}$, as the lateral pressure coefficient increases, the horizontal convergence increases by $60.9 \%$, the vault sinking increases by $19.5 \%$ and the bottom drum increases by $416.5 \%$. When the depth is $300 \mathrm{~m}$, the displacement increases with the lateral pressure coefficient large and increasing variation intervals, horizontal convergence increased by $78.6 \%$, vault sinking increased by $26.9 \%$, the bottom drum increased by $760.5 \%$. In the displacement with the lateral pressure coefficient increases and decreases in the same range can also get similar laws. From this, under certain depth we can conclude tha the lateral pressure coefficient of bottom drum is the most sensitive, followed by horizontal convergence and vault sinking relatively weak. 


\subsubsection{Analysis of the depth of influence}

(1)When the depth of burial is changed from $100 \mathrm{~m}$ to $150 \mathrm{~m}$, the maximum displacement of the horizontal convergence increases by $9.6 \%$, the maximum displacement of the crown sinking increases by $1.3 \%$ and the maximum displacement of bottom uplift increases by $60.3 \%$. And the depth of burial is changed from $150 \mathrm{~m}$ to $200 \mathrm{~m}$, the maximum displacement of the horizontal convergence increased by $7.9 \%$, the maximum displacement of the vault subsidence increased by $7.7 \%$ and the maximum displacement of bottom uplift increased by $2.7 \%$. When the depth of burial is changed from $200 \mathrm{~m}$ to $300 \mathrm{~m}$, the maximum displacement of horizontal convergence increased by $10.6 \%$, the maximum displacement of the dome sinking increased by $4.8 \%$ and the maximum displacement of bottom uplift increased by $1.3 \%$. It can be concluded that as the depth of burial increases, the level convergence, dome subsidence, and bottom uplift displacement all increase in varying degrees.

Table 1 Physical and mechanical parameters of rock mass

\begin{tabular}{|c|c|c|c|c|c|}
\hline $\begin{array}{c}\text { Elastic Modulus } \\
E(\mathrm{Mpa})\end{array}$ & $\begin{array}{c}\text { Poisson's ratio } \\
\mu\end{array}$ & $\begin{array}{c}\text { Unit weight } \\
\gamma\left(\mathrm{KN} / \mathrm{m}^{3}\right)\end{array}$ & $\begin{array}{c}\text { Cohesion } \\
C(\mathrm{Mpa})\end{array}$ & $\begin{array}{c}\text { Internal friction angle } \\
\Phi\left({ }^{\circ}\right)\end{array}$ & $\begin{array}{c}\text { Uniaxial tensile strength } \\
\sigma^{\prime}(\mathrm{Mpa})\end{array}$ \\
\hline 1500 & 0.25 & 27.2 & 0.01 & 25 & 0.1 \\
\hline
\end{tabular}

Table 2 Displacements of tunnel rock mass $(\mathrm{cm})$

\begin{tabular}{|c|c|c|c|c|c|c|c|c|c|c|c|c|}
\hline \multirow{2}{*}{$\begin{array}{c}\text { Side } \\
\text { pressure } \\
\text { coefficient }\end{array}$} & \multicolumn{3}{|c|}{ Buried depth $100 \mathrm{~m}$} & \multicolumn{3}{|c|}{ Buried depth $150 \mathrm{~m}$} & \multicolumn{3}{|c|}{ Buried depth $200 \mathrm{~m}$} & \multicolumn{3}{|c|}{ Buried depth $300 \mathrm{~m}$} \\
\hline & $\begin{array}{l}\text { Horizontal } \\
\text { convergence }\end{array}$ & $\begin{array}{l}\text { Vault } \\
\text { sinks }\end{array}$ & $\begin{array}{c}\text { Bottom } \\
\text { uplift }\end{array}$ & $\begin{array}{l}\text { Horizontal } \\
\text { convergence }\end{array}$ & $\begin{array}{l}\text { Vault } \\
\text { sinks }\end{array}$ & $\begin{array}{c}\text { Bottom } \\
\text { uplift }\end{array}$ & $\begin{array}{l}\text { Horizontal } \\
\text { convergence }\end{array}$ & $\begin{array}{l}\text { Vault } \\
\text { sinks }\end{array}$ & $\begin{array}{c}\text { Bottom } \\
\text { uplift }\end{array}$ & $\begin{array}{l}\text { Horizontal } \\
\text { convergence }\end{array}$ & $\begin{array}{l}\text { Vault } \\
\text { sinks }\end{array}$ & $\begin{array}{c}\text { Bottom } \\
\text { uplift }\end{array}$ \\
\hline 0.1 & 22.40 & 58.93 & 5.97 & 19.74 & 56.19 & 3.40 & 18.48 & 54.10 & 2.60 & 18.15 & 53.41 & 1.58 \\
\hline 0.3 & 24.70 & 59.25 & 7.44 & 22.43 & 60.00 & 4.98 & 18.64 & 54.14 & 3.19 & 17.60 & 52.31 & 1.99 \\
\hline 0.5 & 25.15 & 59.16 & 8.14 & 25.93 & 59.07 & 7.93 & 24.77 & 64.65 & 4.57 & 19.37 & 55.39 & 3.01 \\
\hline 1.2 & 18.49 & 54.80 & 1.82 & 24.68 & 56.98 & 11.02 & 28.78 & 59.59 & 13.40 & 32.91 & 66.51 & 12.32 \\
\hline 1.4 & 17.05 & 53.25 & 1.14 & 23.01 & 56.05 & 7.77 & 26.73 & 57.34 & 12.55 & 32.37 & 64.15 & 13.57 \\
\hline 1.6 & 16.79 & 53.09 & 1.12 & 21.12 & 55.34 & 4.42 & 25.03 & 56.01 & 11.17 & 29.71 & 61.34 & 12.93 \\
\hline 1.8 & 16.95 & 53.41 & 1.18 & 19.13 & 54.29 & 1.96 & 23.72 & 55.70 & 8.82 & 28.03 & 58.61 & 11.65 \\
\hline 2.0 & 17.26 & 53.69 & 1.23 & 17.81 & 53.59 & 1.27 & 22.01 & 55.47 & 6.74 & 26.60 & 56.74 & 10.39 \\
\hline
\end{tabular}

(2) When the depth is $100 \mathrm{~m}$, the variation range of horizontal convergence increases with the increase of lateral pressure coefficient is $\lambda=0.1 \sim 0.5$. The variation of vault subsidence increases with the increase of lateral pressure coefficient is from 0.1 to 0.3 . The variation range of the bottom uplift increasing with the lateral pressure coefficient is $\lambda=0.1 \sim 0.5$. When the depth is $150 \mathrm{~m}$, the variation range of horizontal convergence increases with the increase of lateral compression coefficient is $\lambda=0.1 \sim 0.8$. The variation of vault subsidence increases with the increase of lateral pressure coefficient is from 0.1 to 0.3 . The variation range of bottom uplift increasing with increasing lateral pressure coefficient is $\lambda=0.1 \sim 1.0$. When the depth is $200 \mathrm{~m}$, the variation range of horizontal convergence increases with the increase of lateral compression coefficient is $\lambda=0.1 \sim 1.0$. The variation of vault subsidence increases with the increase of lateral pressure coefficient is from 0.1 to 0.5 . The variation range of the bottom uplift increasing with lateral pressure coefficient is $\lambda=0.1 \sim 1.2$. When the depth is $300 \mathrm{~m}$, the variation range of horizontal convergence increases with the increase of lateral pressure coefficient is $\lambda=0.1 \sim 1.2$. The variation of vault subsidence increases with the increase of lateral pressure coefficient is from 0.1 to 1.0. The variation range of bottom uplift increasing with increasing lateral pressure coefficient is $\lambda=0.1 \sim 1.4$. From this it can be concluded that as the depth of burial increases, the range of variation of horizontal convergence, dome subsidence, and kick movement with the increase of lateral pressure coefficient will widen, with the side pressure coefficient Increased and decreased change intervals narrow.

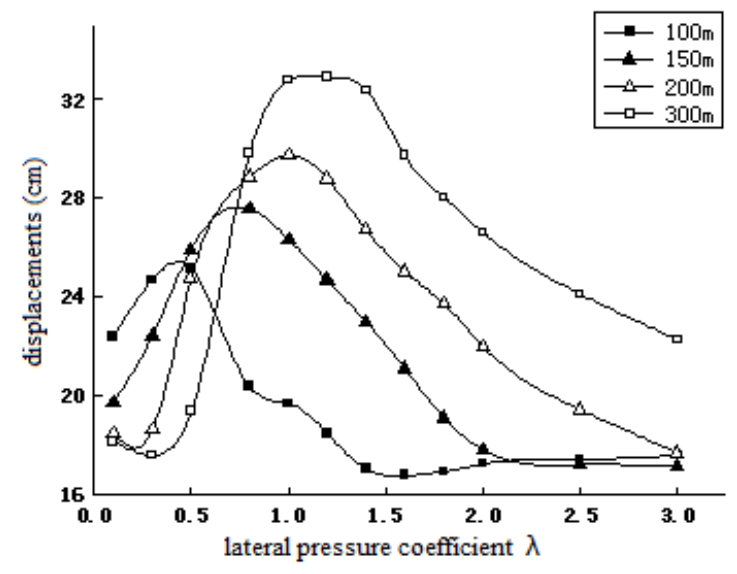

Figure.3 Varying curves of horizontal convergence with lateral pressure coefficient 


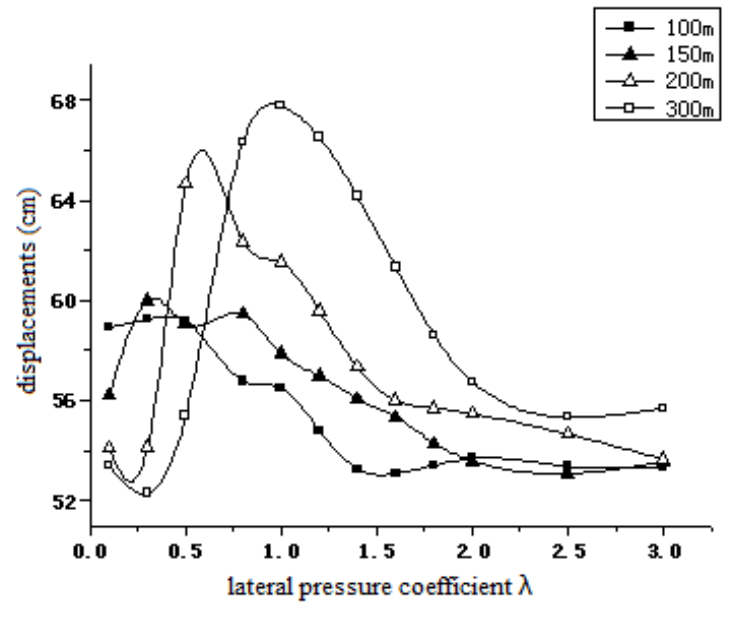

Figure.4 Varying curves of vault subsidence with lateral pressure coefficient

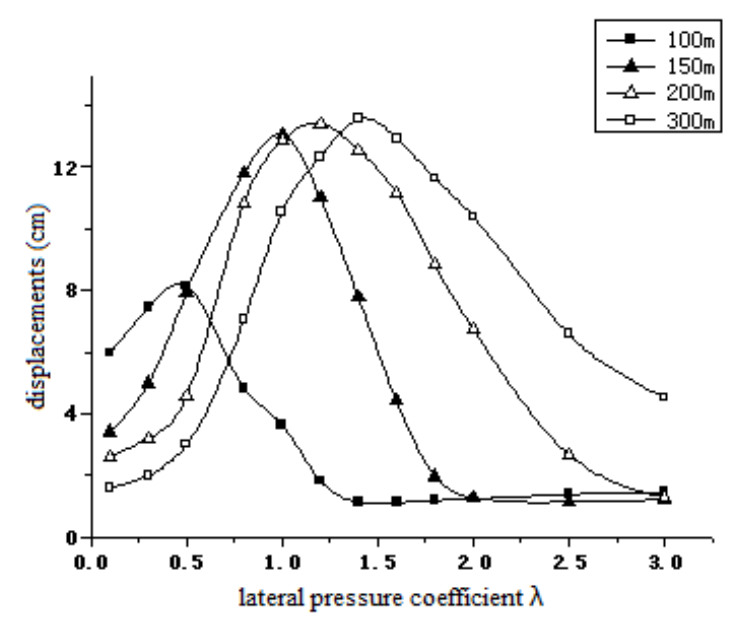

Figure.5 Varying curves of invert heave with lateral pressure coefficient

\section{Conclusion}

In this paper, under the conditions of high ground stress, different lateral pressure coefficients and different depths are combined to simulate the construction of soft surrounding rock tunnel, and the influence of lateral pressure coefficient and depth on the displacement of surrounding rock is analyzed. As a result:

(1) When the buried depth is constant, with the increase of the lateral pressure coefficient, the displacement of the surrounding rock of the tunnel will increase first and then decrease. Among them, the change of lateral pressure coefficient of bottom drum is the most sensitive, followed by horizontal convergence, and the vault sinking is relatively weak.

(2) With the increase of buried depth, the displacement of tunnel surrounding rock increases to some extent. Horizontal convergence, vault sinking and bottom drum displacement increase with increasing lateral pressure coefficient will broaden the range of variation, as the lateral pressure coefficient increases and decreases the narrowing of the change interval.
(3) The research results in this paper have certain guiding significance and reference value for tunnel design and construction measurement under weak surrounding rock conditions.

\section{References}

1. China Institute of Water Resources and Hydropower Research, et al. The Handbook of Parameters of Rock Mechanics[M]. Beijing: China Water\&Power Press, 1991. (in Chinese)

2. M.J.Coetzee, R.D.Hart, P.M.Varona, et al. FLAC Basics[M]. Minneapolis: Itasca Consulting Group, Inc., 1988.

3. Itasca Consulting Group, Inc. FLAC3D version 2.0 User's Manual [M]. Minnesota USA: Itasca Consulting Group, Inc. ,1997.

4. B.Liu, Y.H.Han. Principle, Example and Use Guide of FLAC $[\mathrm{M}]$. Beijing: China Communication Press, 2005. (in Chinese)

5. Y. X. Xia, Y. D. Wang. Structure Mechanics Calculation in Tunnel[M]. Beijing: China Communication Press, 2004. (in Chinese)

6. J.K.Zhang, J.B.Fang. Experiment research on support parameters of large strain phyllite tunnel under high stress[J]. Journal of Railway Engineering Society, 2005,5: 66 70.(in Chinese with English abstract)

7. Z. Q. Zhang, B. S. Guan. Research on the deformation rule of weak rock mass tunnel under high initial geostress[J]. Chinese Journal of Geotechnical Engineering, 2000,22(6): 696 700 . (in Chinese with English abstract) 